Article

\title{
Fuel Classes in Conifer Forests of Southwest Sichuan, China, and Their Implications for Fire Susceptibility
}

\author{
San Wang and Shukui Niu * \\ College of Forestry, Beijing Forestry University, No. 35, Qinghua East Road, Haidian District, Beijing 100083, \\ China; gzwangsan@126.com \\ * Correspondence: bjniushukui@126.com
}

Academic Editors: Yves Bergeron and Sylvie Gauthier

Received: 21 October 2015; Accepted: 23 February 2016; Published: 7 March 2016

\begin{abstract}
The fuel characteristics that influence the initiation and spread of wildfires were measured in Keteleeria fortune forest (FT1), Pinus yunnanensis forest (FT2), P. yunnanensis and Platycladus orientalis (L.) Franco mixed forest (FT3), P. yunnanensis Franch and K. fortunei (Murr.) Carr mixed forest (FT4), Tsuga chinensis forest (FT5), and P. orientalis forest (FT6) in southwest Sichuan Province, China. We compared vertical distributions of four fuel classes (active fuel, fine fuel, medium fuel and thick fuel) in the same vertical strata and in different spatial layers, and analyzed the fire potential (surface fire, passive and active crown fires) of the six forest types (FT). We then classified the six forest types into different groups depending on their wildfire potential. By using the pattern of forest wildfire types that burnt the most number of forests, we identified four fire susceptibility groups. The first two groups had the lowest susceptibility of active crown fires but they differed in the proportion of surface and passive crown fires. The third group was positioned in the middle between types with low and extremely high fire susceptibility; while the fourth group had the highest susceptibility of active crown fires. The results of this study will not only contribute to the prediction of fire behavior, but also will be invaluable for use in forestry management.
\end{abstract}

Keywords: stand characteristics; fire susceptibility; forest types; canonical component analyses

\section{Introduction}

Wildfire is a primary source of natural disturbance in forest ecosystems, and it plays an important role in determining the landscape structure and plant community composition. Wildfires are classified into ground, surface, and crown fires, based on the strata where the burning occurs [1]. For example, the shrub and small trees stratum act as a "ladder fuel" that forms a continuous ladder fuel from the surface fuel up to the canopy fuel, which can turn low-intensity surface fires into severe canopy fires, potentially resulting in active crown fires [2,3]. Crown fires include active crown fires when a solid flame develops in the crown of trees where the surface and crown phases advances as a linked unit dependent on each other. Passive crown fire is where a fire in the crown of the trees in which a tree or group of trees torch, ignited by the passing front of the fire $[1,4,5]$. Fire susceptibility is determined by the distribution, type and continuity of fuel [6]. Assessing the potential of wildfires is an important factor for fire prevention and suppression planning. Forest managers are expressing a growing interest in proactively reducing an area's susceptibility to fires, yet fires remain responsible for a large proportion of the annual area burned in fire-prone ecosystems. Our knowledge of wildfire prevention and its relationship with forest type is lacking [7-9].

Fuels, weather, and terrain are key factors influencing the initiation and spread of wildfires [10], and of these three factors, only fuels can be actively managed [11]. The term "fuel" does not stand for a single object but is a complex multi-layered system, which includes the following layers from surface 
to canopy: a semi-decomposed layer, an active/fine fuel layer, a large fuel layer, a herb layer, a shrub layer and a tree layer [12]. The spatial characteristics of fuel include the quantity, size, and continuity, which mainly affect behavior of the fire, such as the rate of spread and fire intensity $[13,14]$. It would be prohibitively difficult to maintain an inventory of all fuel characteristics because fuel is structurally complex and varies widely in its physical attributes. Thus, an orderly method of classifying fuels and inferring fuel properties from limited observations is needed.

A classification and characterization method simplifies the complexity to a reasonable degree and does not oversimplify the description of forest fuel [15,16]. Since the 1930s, Hornby [17] classified fuels based on their potential rate of spread in the United States. Rothermel [10] developed a mathematical model that allowed consideration of the intensity and rate of spread of fires among reasonably homogenous fuels types, including fire behavior prediction systems. Increasing characterization of different forest types has allowed for the establishment of 13 fuel models to simulate fire intensity and the spread of surface fires through grass, shrub, timber, and logging slash forest types [18]. The BEHAVE model [19] was developed to provide standardized numerical fuelbed descriptions in order to generate reasonable and accurate fire behavior predictions using Rothermel's spread model. This model is the most widely used to predict fire behavior, today, and it greatly increased the demand for quantitative data of different forest types.

Fire spread models were tentatively established by Chinese scholars using the Rothermel model $[9,20,21]$. These models incorporate an assessment of surface and crown fire potential and enable the user (the forest manager) to create and catalogue fuel classes. However, the limitations of these fuel models and the frequent change of forest types make it difficult to apply fuel models that were developed for other regions.

Fires are a natural part of the landscapes of Sichuan Province in southwestern China, so the dynamics of burning are part of their natural ecosystems [22,23]. In Sichuan province, the forested area until the Fifth Forest Resources Inventory was 13,301,500 ha, and was 11.6 ha per capita [9]. During the 29-year period, from 1979 to 2008, there were 4774 wildfires; 90 percent of all wildfires in a given year occur from January to May [9]. Therefore, wildfires are an integral part of the region's ecology and botanical diversity, which makes understanding their dynamics essential for forest management in Sichuan. When a fire occurs, it poses a serious threat to property and safety in regions where natural areas are adjacent to urban areas. Thus, the importance of predicting wildfire behavior in assessing fire potential is a prerequisite for evaluating the effectiveness of fuel management during fire prevention planning [24,25].

Since the 1980s, studies on forest fuel in southwestern Sichuan have assessed the main vegetation types according to fire danger classes [26], the influence of extreme climate on fuel distribution [23], the combustion characteristics of Pinus yunnanensis Franch [20], and control measures for wildfires [27]. However, previous studies did not take into consideration the different forest types that are found in the region, mainly due to the difficulty of determining the potential fire behaviour by forest managers during daily observations. To improve fuel management and fire suppression planning, there is a clear need for additional information on the spatial distribution and classification of fuel types in Sichuan Province.

In this study, we conducted field measurements of forests to classify coniferous forests into forest types as a function of their fire potential. Our study includes detailed field classifications in every layer where different diameters of fuel were found, and their implications for the potential of fire spread at the stand scale. The study objectives were to: (1) compare the spatial distribution of fuel loadings in different coniferous forest types, (2) analyze the fire potential of different conifer forests, and (3) classify the different forest types into different fuel types depending on the pattern of fire types that burned them. 


\section{Materials and Methods}

\subsection{Study Area}

The study area was conducted in the southwestern region of Sichuan Province (between $101^{\circ} 08^{\prime}-103^{\circ} 53^{\prime} \mathrm{E}$ and $\left.26^{\circ} 05^{\prime}-29^{\circ} 27^{\prime} \mathrm{N}\right)$, China, which included two regions, the Liangshan Autonomous Prefecture and Panzhihua City (Figure 1). The region has a dry, subtropical monsoon climate typified by hot summers, warm winters, and slightly more precipitation during the summer than the winter and spring. The annual average temperature of $15^{\circ} \mathrm{C}$ is one of the highest in Sichuan Province, with mean daily temperatures ranging from $13{ }^{\circ} \mathrm{C}$ in winter to $26{ }^{\circ} \mathrm{C}$ in summer. Mean average annual rainfall ranges from 820 to $1160 \mathrm{~mm}$ and is concentrated in the summer, with winter rainfall representing only about $7 \%$ of the annual total. Average annual sunshine ranges between 2000 and $2700 \mathrm{~h}$, relative humidity ranges from $56 \%$ to $71 \%$, while the mean annual average wind speed is $1.75 \mathrm{~m} \cdot \mathrm{s}^{-1}$.

The study site contained $74.2 \%$ mountain, $10.3 \%$ hilly, $8.2 \%$ plain and $7.3 \%$ plateau regions. The elevation is between 186 and $6511 \mathrm{~m}$, and the average slope is $18^{\circ}$ [28]. By the end of 2014, the human population was $81,400,000$. Vegetation mainly includes four types, they are cold-temperate zone coniferous forest, temperate broad-leaved coniferous mixed forest, north-subtropical deciduous and evergreen broad-leaved mixed forest, and mid-subtropical deciduous and evergreen broad-leaved mixed forest.

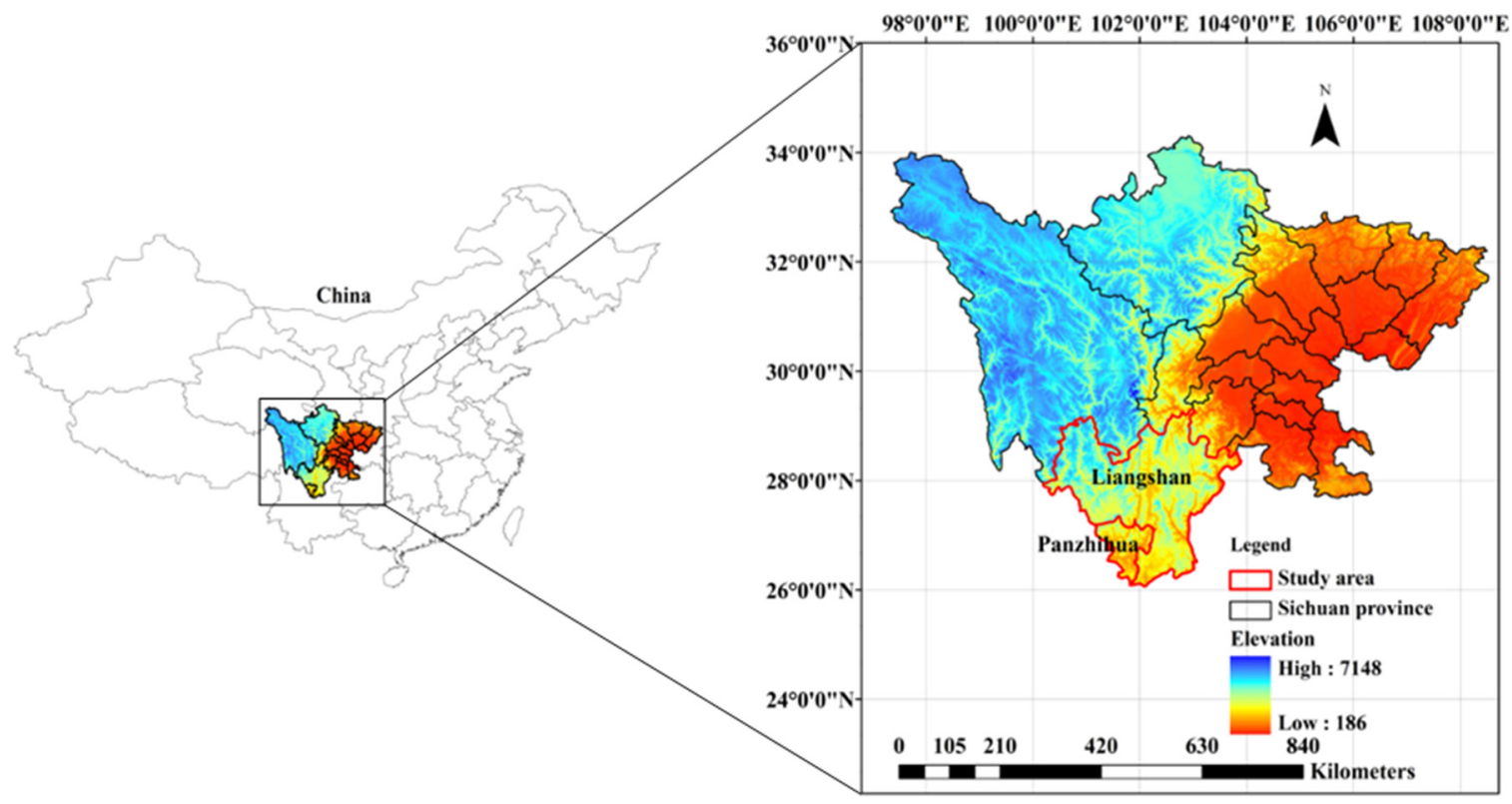

Figure 1. Study area in Sichuan Province, China.

\subsection{Site Selection and Measurements}

During the initial stage of the research, we evaluated candidate sites where wildfires had occurred more than twenty years prior and where no fuel treatment activities had been carried out within the perimeter of the wildfire. We consulted with officials from the Forest Fire Prevention Headquarters Office of Sichuan Province and reviewed wildfire records to determine the suitability of sites, identifying six forest types (hereafter, FT) that met our selection criteria: Keteleeria fortune forest (FT1), Pinus yunnanensis forest (FT2), P. yunnanensis and Platycladus orientalis (L.) Franco mixed forest (FT3), P. yunnanensis Franch and K. fortunei (Murr.) Carr mixed forest (FT4), Tsuga chinensis forest (FT5), and $P$. orientalis forest (FT6). We avoided selecting locations with confounding influences that likely changed the wildfire potential, such as roads, rivers, or constructed firelines. For each selected forest type, three to five transects that spanned the area were placed parallel to each other and 100 meters 
apart [15]. We aimed to locate different stands with the same species composition and to minimize differences due to topography and local climate by selecting transects that were in close proximity to each other. Three to ten fuel plots were established at 100-m intervals along each transect based on the size of the forested area and variability in landforms. A plot area covering $400 \mathrm{~m}^{2}(20 \mathrm{~m} \times 20 \mathrm{~m})$ was used to measure the fuel composition [14]. A total of 5 transects (45 plots) were sampled in FT1, 4 transects ( 37 plots) in FT2, 5 transects (44 plots) in FT3, 5 transects (48 plots) in FT4, 4 transects ( 36 plots) in FT5, and 5 transects ( 43 plots) in FT6. A total of 28 transects ( 253 plots) were sampled in the six forest types.

We considered all trees higher than $3 \mathrm{~m}$ in each plot and we classified them into three classes: small $(3-5 \mathrm{~m})$, medium $(5-8 \mathrm{~m})$ and large trees $(>8 \mathrm{~m})$. Then, we measured the following: diameter at breast height, height, age, canopy closure, canopy base height and canopy width. The initial classification of stands was based on site specific data including elevation, slope, and aspect. Total height and the height to the live crown base were measured with a hypsometer laser Vertex III [29]. The canopy closure in each plot was estimated using a spherical densitometer [30], and the slope was measured with a forest compass [31]. The elevation was estimated by GPS.

\subsection{Forest Fuel Profiles}

\subsubsection{Crown Layer}

We estimated the crown fuel loading using the following steps:

(1) Selection of standard wood: In each plot, two trees in the forests composed of single species and three to five trees in mixed forests were randomly chosen as standard wood (SW) from each representative forest (FT1-FT6). The selection criteria were as follows: (1) the difference was no more than $\pm 10 \%$ between the diameter of standard wood and the average diameter; (2) the difference was no more than $\pm 5 \%$ between the height of standard wood and average height [14].

(2) Selection of standard branches (SB): We selected three live and three dead standard branches (SB) for each species of SW in each plot, and calculated the average wet weight of an SB for each species. An SB was representative of the size and distribution of other branches. Then, standard branches were divided into six components (see (4)) based on diameter. Determining standard branches provides an advantage by providing information about the amount of fuel per tree without cutting down the trees. For other examples of standard branches used in forestry studies, see Zhang [28], and Niu [14].

(3) The crown fuel was divided into 11 vertical layers: $0-1,1-2,2-3,3-4,4-5,5-6,6-7,7-8,8-9$, 9-10, and above $10 \mathrm{~m}$. The number of live and dead SBs $(\mathrm{N})$ in every layer of the tree was recorded.

(4) SBs were divided into six components, based on diameter (D): (1) dead fuel, (a) 1-h fuels ( $D<0.64 \mathrm{~cm}$ ), (b) 10 -h fuels (woody biomass $0.64 \leqslant D<2.54 \mathrm{~cm}$ ), (c) 100 -h fuels $(2.54 \leqslant D<7.6 \mathrm{~cm}$ ), and (d) 1000-h fuels ( $D \geqslant 7.6 \mathrm{~cm})$; and (2) live fuel, (a) foliage and twig $(\leqslant 1 \mathrm{~cm})$, and (b) big branch $(1<D \leqslant 10 \mathrm{~cm})$ [32]. All the SB harvested material was weighed by size class to the nearest gram using a digital scale in the field [33]. After that, subsamples of each SB size class were taken back to the laboratory to be weighted, and oven dried at $105^{\circ} \mathrm{C}$ [34], then weighed again [14].

(5) Calculations

Formula 1 was used to calculate the ratio of the fresh and dry (R) material.

$$
R=\frac{W_{D}}{W_{N}}
$$

where $R$ is fuel ratio of the wet and dry $(\mathrm{g}), W_{N}$ is the wet weight of the fuel $(\mathrm{g})$, and $W_{D}$ is the dry weight of the fuel $(\mathrm{g})$. The fuel loading $(W)$ was calculated with Equation (2).

$$
W=\frac{N \sum_{i=1}^{n} F_{i} R}{1000 S H}
$$


where $W$ is the canopy bulk density $\left(\mathrm{kg} \cdot \mathrm{m}^{-3}\right), F_{i}$ is the fresh weight of the $i$ th SB fuel classes $(\mathrm{g}), N$ is the number of $\mathrm{SBs}$, and $S$ is the area of the site $\left(\mathrm{m}^{2}\right), H$ is the height of every layer.

\subsubsection{Shrub and Herb Layer}

We determined the shrub and herb species, the total number of each species, and their height $(\mathrm{cm})$ and weight (g) in $2 \mathrm{~m} \times 2 \mathrm{~m}$ quadrats for shrubs and $1 \mathrm{~m} \times 1 \mathrm{~m}$ quadrats for herbs within the plots at each of the four corners and in the center using the clear cut method. All shrub and herb harvested material was weighed by their size classes to the nearest gram using a digital scale [33]. After that, subsamples of each the shrub and herb size class were taken back to the laboratory to be weighed and dried at $105^{\circ} \mathrm{C}$ [34], then weighed again [14].

\subsubsection{Surface Dead Layer}

In $1 \mathrm{~m} \times 1 \mathrm{~m}$ sampling quadrats, we investigated the thickness and type of litter layers (leaves, cones, and bark) and dead fuels (1-h, 10-h, 100-h,and 1000-h) [35]. All litter and dead fuel harvested material was weighed by their size classes to the nearest gram using a digital scale [33]. After that, subsamples of each litter size class were taken back to the laboratory to be weighed and dried at $105^{\circ} \mathrm{C}$ [34], then weighed again [14].

We calculated the loading of shrubs, herbs and surface dead fuel with Equation (3):

$$
W=\frac{F_{i} R}{1000 S}
$$

where $W$ is the fuel loading $\left(\mathrm{kg} \cdot \mathrm{m}^{-2}\right), S$ is the area of the quadrats, and $F_{i}$ is the fresh weight of the shrubs, herbs and dead surface fuel $(\mathrm{g}), R$ is the ratio of the fresh to dry material.

\subsection{Data Analysis}

We separated surface and crown fuel into four fuel classes: (1) active fuel (litter layers and 1-h), (2) fine fuel (herbs, foliage and 10-h), (3) medium fuel (branches $(D \leqslant 1 \mathrm{~cm})$ and 100-h), and (4) thick fuel (branches $(1<D \leqslant 10 \mathrm{~cm})$ and 1000-h) [36-39] (1-h, 10-h, 100-h, 1000-h from the tree or dead surface fuels). There are many factors that affect the combustion characteristics of fuel, such as species, continuity, and moisture content; however, we focused on the diameter of the fuel in this paper.

The homogeneity of variances and the normality of distribution were determined for the six forest types and four fuel classes using the least significant difference (LSD) multiple comparison method. To clearly illustrate the spatial distribution of surface fuel, we analyzed the surface fuel loading as a variable using descriptive statistics-frequencies. The statistical analyses were performed with SPSS software (version 18.0), and differences were considered significant at the level of $\alpha=0.05$.

\subsection{Fire Behavior Simulations}

We consulted with officials from the Forest Fire Prevention Headquarters Office of Sichuan Province, reviewed wildfire records, and the meteorological conditions to determine three burning conditions: low (fuel moisture of $15 \%$ and a wind speed of $5 \mathrm{~km} \cdot \mathrm{h}^{-1}$ ), moderate (fuel moisture of $10 \%$ and a wind speed of $15 \mathrm{~km} \cdot \mathrm{h}^{-1}$ ), and extreme (fuel moisture of $5 \%$ and a wind speed of $30 \mathrm{~km} \cdot \mathrm{h}^{-1}$ ). We conducted separate analyses for each plot depending on plot location and the three burning conditions. All of the wind values refer to 10-m open windspeeds. The wind adjustment factor was considered as 0.3 , which was applied to all fuel models. Heat content values for all simulations were obtained from Niu's [14] work. Fire intensity and spread rate of a crown fire were evaluated using Rothermel's [10] surface fire spread model and Rothermel's [40] crown fire spread model, respectively, using BehavePlus v. 5.0.4 [41]. We used the custom fuel model and set many parameters (surface fuel loading, crown fuel density of each plot, moisture content, heat content values, canopy base height, wind speed and slope). According to the simulated effects of the fire on the plot and the neighboring 
plot, we distinguished three fire types (surface fires, passive crown fires, and active crown fires) by Alvarez's [29] criterion.

We used canonical component analyses (CCA) to evaluate the differences among the six forest types in terms of outcome of fire type under extreme fire weather conditions. The environmental dataset included tree age, height, elevation, slope, aspect, density, canopy closure, and diameter at breast height (DBH) in each plot. The environmental data were measured in the field except aspect need to be converted by digitizing in the calculation process [13]. Additionally, the fire type in each plot (under extreme burning conditions) was considered the "species" in the data matrix. From these analyses, we identified the groups of forest types that showed a similar response, yet could be considered different fire types. We did not measure ground fires because in these unmanaged forests, ground fires are commonly absent.

\section{Results}

\subsection{Description of Six ForestTypes}

We described each forest type with statistics on surface fuel horizontal continuity, canopy closure, and fuel horizontal (which had been measured through the density and canopy width) and vertical continuity (which had been measured through the proportion on trees in different height class and vertical distribution of fuel classes). Results are summarized in Tables 1-3 and Figures 2 and 3.

Forest Type 1 (FT1) had three layers, a high density of stems (Table 1) that contributed to its very high horizontal continuity, vertical continuity and high canopy fuel loading (Figure 3). As the height of trees increased, active fuel declined gradually, while fine fuel, medium fuel, and thick fuel increased gradually. Only fine fuel, medium fuel, and thick fuel were distributed above $7 \mathrm{~m}$ (Figure 3). This gap in the canopy also led to a high understory density. The surface continuity had a loading between 0.50 and $0.75 \mathrm{~kg} \cdot \mathrm{m}^{2}$, which accounted for about $80 \%$ of the total loading, while more than $0.90 \mathrm{~kg} \cdot \mathrm{m}^{-2}$ accounted only for $6.7 \%$ (Figure 2).

Table 1. Mean of the variables used to describe the six forest types identified in southwest Sichuan Province, China.

\begin{tabular}{|c|c|c|c|c|c|c|c|c|c|c|c|c|}
\hline $\begin{array}{l}\text { Forest } \\
\text { types }\end{array}$ & $\mathbf{N}$ & $\begin{array}{l}\text { Canopy } \\
\text { Closure }\end{array}$ & $\begin{array}{c}\text { Diameter at } \\
\text { Breast } \\
\text { Height }(\mathrm{cm})\end{array}$ & $\underset{\text { (m) }}{\text { Height }}$ & $\begin{array}{l}\text { Crown } \\
\text { Width } \\
\text { (m) }\end{array}$ & $\begin{array}{c}\text { Small } \\
\text { Trees } \\
(\%)\end{array}$ & $\begin{array}{c}\text { Medium } \\
\text { Trees } \\
(\%)\end{array}$ & $\begin{array}{c}\text { Large } \\
\text { Trees } \\
(\%)\end{array}$ & Slope $\left(^{\circ}\right)$ & $\begin{array}{c}\text { Elevation } \\
(\mathrm{m})\end{array}$ & Aspect & $\begin{array}{l}\text { Tree } \\
\text { Age }\end{array}$ \\
\hline FT1 & 45 & 0.8 & $11.8(4.6)$ & $\begin{array}{l}10.7 \\
(0.7)\end{array}$ & $3.5(0.3)$ & $20(6)$ & $15(4)$ & $65(16)$ & $28(2)$ & \multirow{6}{*}{$\begin{array}{l}1507 \\
(20) \\
1598 \\
(21) \\
1609 \\
(27) \\
1509 \\
(32) \\
3014 \\
(25) \\
1551 \\
(35)\end{array}$} & NW & $37(1)$ \\
\hline FT2 & 37 & 0.7 & $16.5(3.6)$ & $\begin{array}{l}10.9 \\
(1.1)\end{array}$ & $4.1(0.9)$ & 0 & $6(2)$ & 94 (11) & $30(1)$ & & SW & $30(2)$ \\
\hline FT3 & 44 & 0.7 & $10.9(3.2)$ & $\begin{array}{l}12.7 \\
(2.1)\end{array}$ & $2.2(0.3)$ & $27(4)$ & $4(1)$ & $71(10)$ & $27(2)$ & & NE & $28(2)$ \\
\hline FT4 & 48 & 0.6 & $14.6(4.1)$ & $\begin{array}{l}10.3 \\
(1.7)\end{array}$ & $2.6(0.5)$ & $26(3)$ & $23(3)$ & 51 (12) & $35(2)$ & & SW & $35(3)$ \\
\hline FT5 & 36 & 0.8 & $12.0(5.3)$ & $\begin{array}{l}12.8 \\
(0.9)\end{array}$ & $3.2(1.6)$ & $17(2)$ & $65(7)$ & $18(8)$ & $34(1)$ & & NE & $30(1)$ \\
\hline FT6 & 43 & 0.6 & $7.4(2.9)$ & $\begin{array}{l}10.5 \\
(0.8)\end{array}$ & $1.6(0.5)$ & $33(7)$ & $33(9)$ & $44(9)$ & $30(3)$ & & NW & $40(5)$ \\
\hline
\end{tabular}

Forest Type 2 (FT2) was a simple structure that was characterized by a layer of large trees $(>90 \%)$ with lower values of surface structure, canopy fuel loading, and tree density (Tables 1 and 2 and Figure 3). FT2 had the lowest small-sized trees, the lowest canopy base height, the highest value of DBH, and largest crown width. Therefore, FT2 had low vertical and high horizontal continuity. The total surface fuel loading was significantly lower than the other two forests that contained P. yunnanensis forests (Table 2). FT2 contained three fuel classes (active fuel, fine fuel, and thick fuel) on the surface. Thick fuel was significantly different from the other forests at the $p$-value of 0.05 . The active fuel loading in FT2 was more than $0.14 \mathrm{~kg} \cdot \mathrm{m}^{-2}$, which accounted for $41 \%$ of the total loading. The horizontal distributions had mid-continuity (Figure 3). Due to its large crown width and the low light levels at the forest floor, FT2 had the lowest understory density. 
Table 2. Loadings of surface fuel classes (active fuel, fine fuel, medium fuel and thick fuel) by six forest types (unit: $\mathrm{kg} \cdot \mathrm{m}^{-2}$ ).

\begin{tabular}{cccccc}
\hline Forest types & Active Fuel & Fine Fuel & Medium Fuel & Thick Fuel & Total \\
\hline FT1 & $0.30(0.07)$ & $0.04(0.01)$ & $0.08(0.03)$ & $0.20(0.07)$ & $0.62(0.10)$ \\
FT2 & $0.14(0.04)$ & $0.07(0.01)$ & 0.00 & $0.13(0.05)$ & $0.34(0.08)$ \\
FT3 & $0.63(0.16)$ & $0.05(0.01)$ & 0.00 & $0.36(0.14)$ & $1.04(0.15)$ \\
FT4 & $0.25(0.06)$ & $0.08(0.01)$ & $0.18(0.04)$ & $0.16(0.05)$ & $0.67(0.07)$ \\
FT5 & $1.11(0.25)$ & $0.60(0.17)$ & $0.06(0.01)$ & $0.57(0.17)$ & $2.34(0.72)$ \\
FT6 & $0.16(0.04)$ & $0.02(0.01)$ & 0.00 & $0.05(0.01)$ & $0.23(0.07)$ \\
\hline
\end{tabular}

The number in parentheses is the standard deviation.

Table 3. Percent of fire types (surface (S), Passive crown fire (P) and Active crown fire (A) from simulation of different fire weather scenarios at $10 \mathrm{~m}$ wind speed $(U)$, and fuel moisture content $\left(M_{f}\right)$ for the six forest types. Fire types were derived according to Alvarez [29] fire spread criteria and Rothermel's [10] surface fire spread model and Rothermel's [41] crown fire spread model.

\begin{tabular}{|c|c|c|c|c|c|c|c|c|c|}
\hline \multirow{2}{*}{$\begin{array}{l}\text { Forest } \\
\text { types }\end{array}$} & \multicolumn{3}{|c|}{$\begin{array}{c}\text { Low } \\
\left(U=5 \mathrm{~km} \cdot \mathrm{h}^{-1}, M f=15 \%\right)\end{array}$} & \multicolumn{3}{|c|}{$\begin{array}{c}\text { Moderate } \\
\left(U=15 \mathrm{~km} \cdot \mathrm{h}^{-1}, M f=\mathbf{1 0} \%\right)\end{array}$} & \multicolumn{3}{|c|}{$\begin{array}{c}\text { Extreme } \\
\left(U=30 \mathrm{~km} \cdot \mathrm{h}^{-1}, M f=5 \%\right)\end{array}$} \\
\hline & $S$ & $\mathbf{P}$ & A & $S$ & $\mathbf{P}$ & A & $S$ & $\mathbf{P}$ & A \\
\hline FT1 & 78 & 22 & 0 & 33 & 38 & 29 & 22 & 45 & 33 \\
\hline FT2 & 100 & 0 & 0 & 85 & 15 & 0 & 70 & 30 & 0 \\
\hline FT3 & 80 & 20 & 0 & 32 & 47 & 21 & 0 & 25 & 75 \\
\hline FT4 & 79 & 21 & 0 & 30 & 35 & 35 & 0 & 39 & 61 \\
\hline FT5 & 95 & 5 & 0 & 40 & 45 & 15 & 0 & 8 & 92 \\
\hline FT6 & 87 & 13 & 0 & 27 & 65 & 8 & 0 & 17 & 83 \\
\hline
\end{tabular}

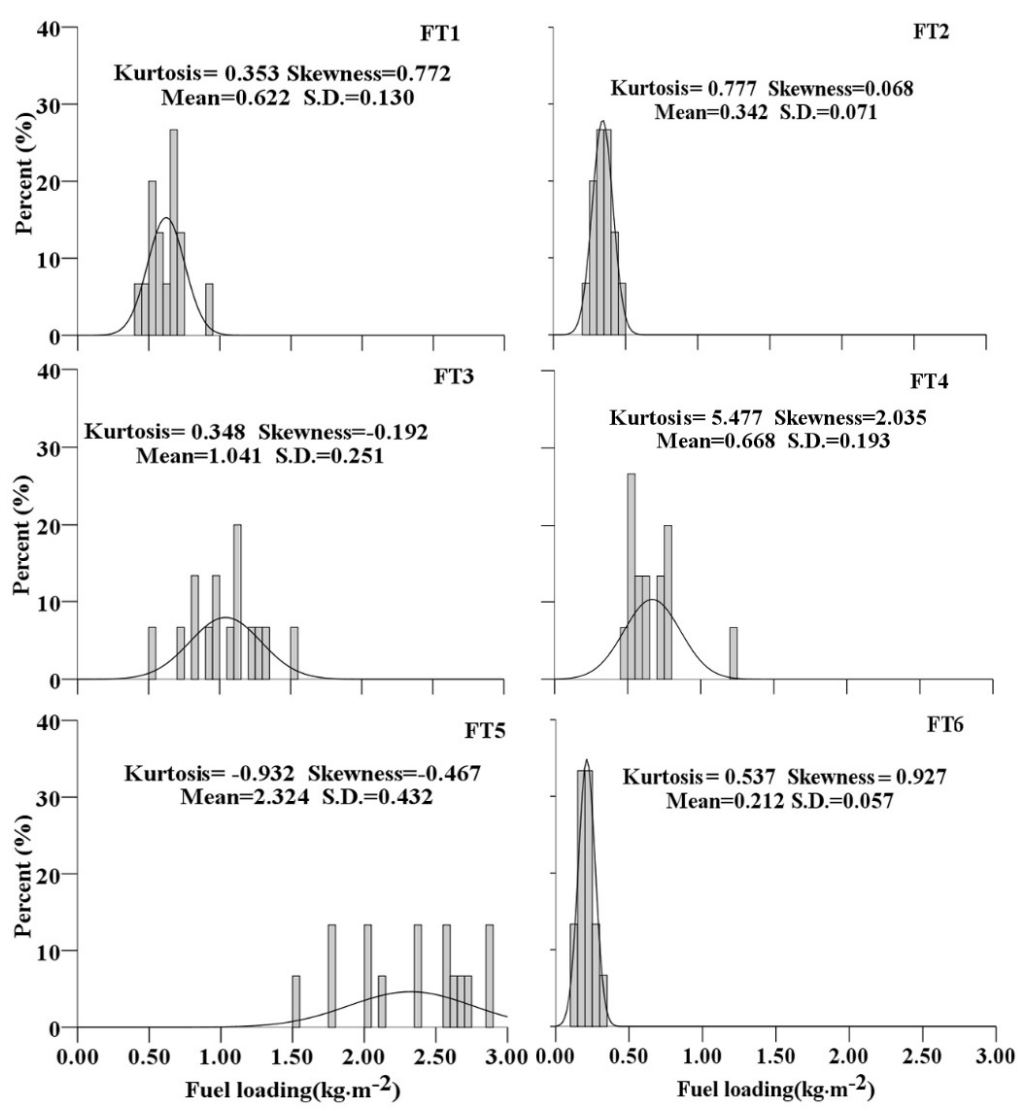

Figure 2. Observed (bar) and fitted (curve) distributions of surface fuel loading by six forest types. 


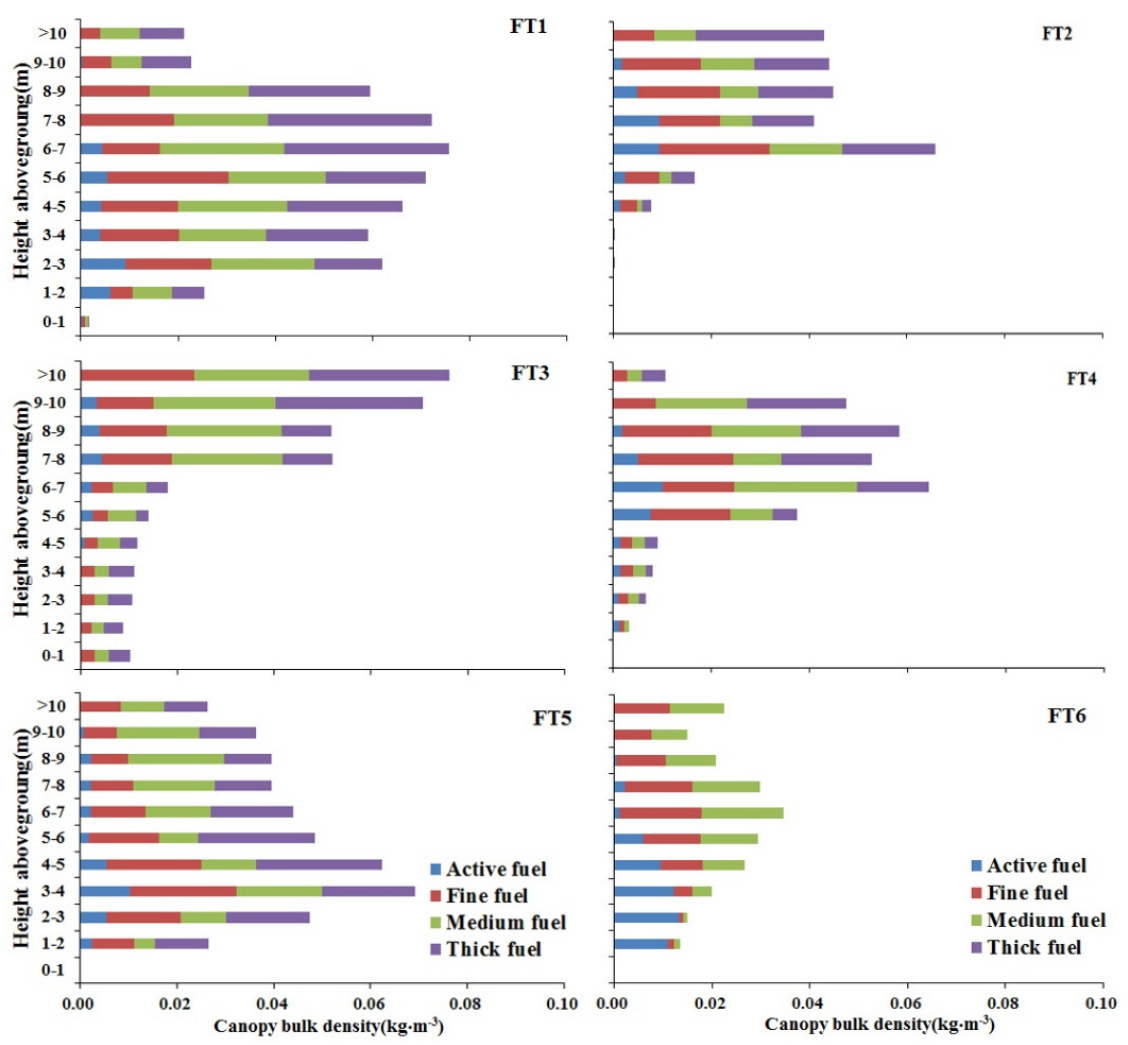

Figure 3. A vertical profile of the aboveground canopy bulk density of four fuel classes in six forest types.

Forest Type 3 (FT3) was a structure with a layer of large trees (percent of large trees was 50\%) and a second layer of medium and small trees that contributed to its higher vertical continuity. FT3 had a higher tree density and canopy base height than FT2. The crown distribution of the various fuel classes in each layer was different (Figure 3), but the total fuel loading increased sharply above $10 \mathrm{~m}$. However, there was a small quantity of loading between $6 \mathrm{~m}$ to $7 \mathrm{~m}$. Active fuel was only distributed between $4 \mathrm{~m}$ and $9 \mathrm{~m}$ (Figure 3). Surface fuels were also distributed relatively heterogeneously, though not to the degree as we observed in FT5 (Figure 3).

Forest Type 4 (FT4) had three layers, the first layer was composed of large trees, small trees and medium trees were almost identical ( $26 \%$ versus $23 \%)$. Almost all fuel classes were distributed in each canopy layer, which reached a maximum between 5 and $8 \mathrm{~m}$; however, there was a small quantity of loading between $1 \mathrm{~m}$ and $5 \mathrm{~m}$. The loading of active fuel was $0.25 \mathrm{~kg} \cdot \mathrm{m}^{-2}$, which accounted for $37 \%$ of the total loading in the type (Table 2). The surface fuel distribution was continuous enough to allow for the spread of a surface fire.

Forest Type 5 (FT5) was an irregular structure that contained three layers (each with a proportion of $17 \%$ to $65 \%$ ), and had a medium tree density $(>60 \%)$ and high vertical continuity (Figure 3 ). Structure and loading in the crown were similar in the layers above $1 \mathrm{~m}$. The moss attached to branches acted as a ladder that allowed the fire to climb up to the crown. The surface loading of active fuel $\left(1.11 \mathrm{~kg} \cdot \mathrm{m}^{-2}\right)$, fine fuel $\left(0.60 \mathrm{~kg} \cdot \mathrm{m}^{-2}\right)$, and thick fuel $\left(0.57 \mathrm{~kg} \cdot \mathrm{m}^{-2}\right)$ reached a maximum among the six forests (Table 2). Surface fuels had the lowest horizontal discontinuity compared with the other forest types, and we observed a large area of bare grounds (Figure 3).

Finally, Forest Type 6 (FT6) was also a three-layer structure, with high vertical continuity and a low density of stems that resulted in this forest type having the lowest horizontal continuity and canopy loading. The majority of crown loading was fine fuel and medium fuel (>70\%). Active fuel declined gradually as the height of the trees increased, while fine fuel and medium fuel increased gradually with an increase in tree height. Although the high horizontal continuity of surface fuels in 
these plots would be conducive to fire spread (Figure 2), the low fuel loadings would only support low intensity surface fires.

\subsection{Pattern of Fire Types Burning in the Different Forest Types}

We compared the pattern of fire types between different forests types under three burning conditions (low, moderate and extreme) in Table 3. In the low burning condition, there were only surface fire and passive crown fires. Under low burning conditions, only surface fires occurred in FT2 because the fuel structure had the lowest vertical continuity and highest horizontal continuity. In FT5, five percent of the fires were passive crown fires and the remaining were surface fires (Tables 1 and 3 , Figure 3). FT4 and FT3 had similar proportions of surface fire, while FT1 and FT6 had similar fire types. Compared to low burning conditions, a proportion of passive crown fires occurred in all forest types under moderate burning conditions and extreme burning conditions because of low moisture content and high wind alignment. Under extreme burning conditions, there were high proportions of plots burning with active crown fires in all forests except FT2. There was no active crown fires in FT2 and $70 \%$ of the fires remained as surface fires burning under extreme conditions.

\subsection{The Differences among the Six Forest Types Using CCA}

Figure 4 illustrates the differences in fire type outcome among the six forest types as viewed using CCA. The first axis of this analysis explained $78.9 \%$ of the variance in fire type under extreme conditions. Four groups could be differentiated based on our CCA (Figure 4A). FT1 was significantly different from all of the other forest types and was located at the positive end of axis 1, and is likely in this location due to the higher surface fuel (Table 2), canopy fuel loading (Figure 3) and tree density (Table 1).The lower left of the diagram contained FT5 and FT6, showing that the interaction between the environmental factors and stand structure influenced the entire fuel "system". FT4 and FT3 emerged to the right of axis 2, and FT2 was located on the bottom right of the diagram. According to Figure 4B, the first axis contained positive values that were associated with density $(r=0.865)$, diameter at breast height $(r=0.623)$, and canopy closure $(r=0.616)$; the second axis contained positive values that were associated with height $(r=0.605)$ and negative values associated with aspect $(r=-0.668)$, The slope, tree age and diameter at breast height had a lesser influence as indicated by the small arrow length compared to height, density, elevation and canopy closure.
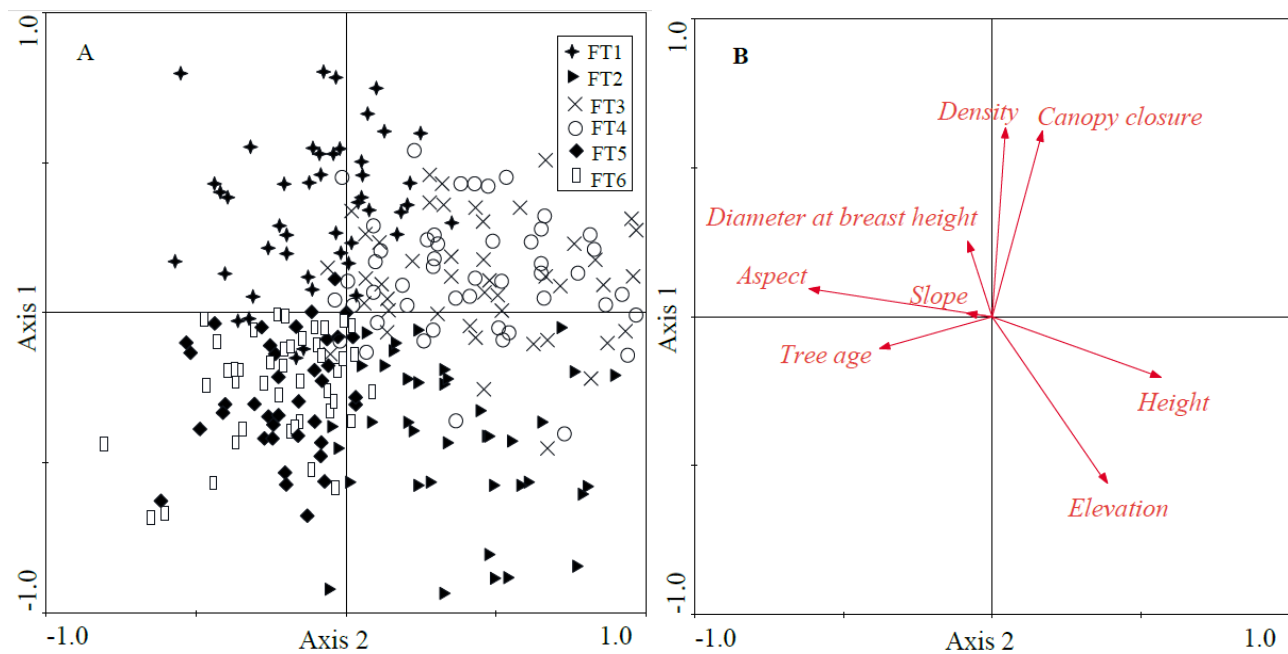

Figure 4. Representation of (A) plots of the six forest types and (B) environmental factor variables on the first two axes of the canonical component analysis. $n=253$ plots. 


\section{Discussion}

Our results indicated that the distribution and structure of four fuel classes, the total loading and fire potential differed among the six forest types. Using CCA analysis, four groups of FT were differentiated (FT1), (FT2), (FT4 and FT3), and (FT5 and FT6), had characteristics in common that determined the type of fires that burned them under the extreme burning condition. The results of the predicted fire potential indicated that the presence of a particular forest type could increase the susceptibility of active crown fires. Thus, less understory loading at the plot level but continuous distribution and lower fuel moisture could have the same effect in initiating crown fires as a higher amount of understory. It is possible that wind speed and continuity are the key elements for the transition from a surface fire to a passive crown fire and, later, to an active crown fire. Niu [14] suggested that the highest increase in size and severity of fires occur with higher vertical and horizontal fuel continuity. Larger crown width, higher canopy fuel loading, and higher density of trees increase the horizontal continuity and created favorable opportunities for the spread of crown fire. Vertical continuity increased with the presence of three tree layers and the "ladder fuel" that provides continuity from the surface fuel to canopy fuel. The FT1 has an increased susceptibility of having active crown fires due to a high tree density and canopy fuel loading, which result in high horizontal continuity and high density as well as a lower live crown with vertical continuity of branches that result in a high vertical continuity. However, FT1 did not generate the highest percentage of active crown fires (Table 3). This may be due to unsuitable conditions to initiate crown fires, such as the proportion of medium fuel and thick fuel being higher than $68 \%$, which can raise the ignition point [14], or due to a lower wind speed as a consequence of it being a dense forest [42]. Thus, FT1 had a high minefield of potential susceptibility for generating active crown fires, but the conditions for crown fire initiation were lower.

Compared to FT1, the susceptibility of having active crown fires in FT5 can increase by the increment of ladder fuels (represented by medium trees, or small trees, especially with epiphytic moss) (Tables 1 and 3). Thus, irregular understory density and lower fuel moisture can lead to the highest susceptibility of surface fires transiting to active crown fires. According to the historical fire record, surface, ground and crown fires occurred simultaneously, which caused irreversible damage. Only two fires (with burn areas of 948 and 666 ha, both in March 1999) occurred in FT5 in March 1999 when there was little rainfall. In meteorological records, there were 74 consecutive days without rain fall in our study area. Therefore, the identification of FT5 is important for suppression planning, because it generate fires with behavior exceeding the extinction capacity. It would be best to reduce the amount of ladder fuels by thinning from below, as well as small diameter trees, cutting shrubs and herbs $[43,44]$. Additionally, pruning the crown to a half or third of the height of the tree could help to reduce ladder fuels. It is possible to also immediately fell a few trees to reduce the canopy density and break the horizontal continuity.

FT2 had a single layer with large trees, low surface fuel loading, and a high canopy base height that originated the most surface fires without any active crown fire initiation (Tables 2 and 3, Figure 3). The fuel quantity, structure and continuity of four fuel classes in FT2 makes the transition to crown fire more difficult (Table 3, Figure 3). However, combined with the higher horizontal continuity of the surface in this type, contributes to greater spreading for surface fires (Figure 2). Therefore, cleaning the surface fuel could help suppress the initiation of surface fire.

The type that resulted in the highest instances of passive and active crown fires was FT6 (Table 3), which had a structure with three layers of small trees, medium trees and large trees (Table 1), and higher vertical continuity (Figure 3). In addition, FT6 only included three fuel classes in the crown: active fuel, fine fuel and medium fuel (active fuel + fine fuel $>60 \%$ ). As a consequence, crown fires can consume more biomass due to the presence of active fuel and fine fuel above a critical rate. This critical spread sustains passive crown fires, which increases the spread, and causes a larger consumption of trees, including active fuel and fine fuel [45]. FT6 would benefit from the removal of some "ladder fuels" to reduce the canopy density. This could be effective in stopping passive crown fires and 
preventing the start of new fires, especially if it was combined with patchy canopy and vertical layer management $[13,14,29]$.

The increment of fuels confirms that types similar to FT6, but with higher vertical continuity (e.g., FT3 and FT4) caused by ladder fuels and higher canopy loading, can increase the susceptibility of having active crown fires (Figure 3). The two types that caused moderate passive crown fires and active crown fires were FT4 and FT3, which had middle-range canopy fuel loading (Figure 3) and tree density (Table 1). FT3 and FT4 had higher spreading for surface fires compared to FT6, which could be caused by higher continuity (Figure 2) and the large quantity of active fuel and fine fuel, which can cause easy spreading [22]. It had a high spread of surface fire that climbed up to the canopy because of the distribution of active fuel and fine fuel between $0 \mathrm{~m}$ and $1 \mathrm{~m}$. FT3 and FT4 are effective in stopping active crown fires and preventing the start of new active crown fires if the canopy continuity is lessened by the removal of small trees.

\section{Conclusions}

Loading and continuity of surface fuels are an important element in determining the spread of surface fire and the transition. The higher continuity of certain forest types results in higher spreading susceptibility of crown fire spread. Ladder fuels result in vertical continuity, which can increase the susceptibility of having active crown fires; large crown width, high canopy fuel loading and tree density increase horizontal continuity and create favorable conditions for burning.

As a consequence, the six forest types have two effects on fire behavior: on one hand they favor the ignition of an active crown with vertical continuity of fuels classes, which determines crown fire initiation; on the other hand, there could be a point of a new crown fire run because of horizontal continuity through the canopy layer, which determines crown fire spread. Forestry managers should take into consideration fuel management and preventive silviculture to estimate the susceptibility of wildfire for the following two reasons. Firstly, this strategy can be effective to stop passive crown fires and also prevent new fires when combined with surface/crown patchiness, understory management and "ladder fuel" management. Several measures can be taken to achieve this goal, such as reducing surface fuel (needles, leaves, grass, dead and down branch wood) [46], and reducing the amount of ladder fuels (small trees and shrubs) $[14,28,29]$. The pruned plant material can be masticated or chipped and left on site, which is an option an increasing number of forest managers are using [24,28]. The pruning can increase the gap between the surface fuel and the crown base height up to $3 \mathrm{~m}$, effectively breaking the continuity of the distribution of the surface fuel $[14,26]$. Secondly, this strategy could be effective in stopping active crown fire if combined with canopy patchiness of low density and canopy fuel loading management. According to Hall and Burke [47], crown fuel structure is a critical factor determining whether crown fires occur. Treatments to reduce crown fire susceptibility often focus on reducing canopy fuels and interrupting the surface-canopy fuel continuum. Combining this with a lower vertical and horizontal continuity makes the transition to crown fire more difficult [29]. Horizontal patchiness of the canopy will reduce the spread of fire within the canopy layer [29], using measures such as cleaning up litter (active fuel and fine fuel) [24], increasing canopy gaps [48], and decreasing tree density [28].

Acknowledgments: This study is part of the Special Research Program for Public-welfare Forestry: Responses of forests to climate change and adaptive strategy of forestry in China, Grant No. 200804001. This research was also supported by National Forest Science and Technology Promotion Project: Medium-long-term and multi-spatio-temporal scales prediction technologies and demonstration of forest fire in Yunnan Province, Grant No. 2015-04. Thanks are given to the Headquarters of Forest Fire Prevention, Sichuan Province, for useful fire data in the statistical analysis. We would also like to thank the Command College of the Armed Police Forces, Beijing, China, for this experiment.

Author Contributions: San Wang and Shukui Niu conceived and designed the study. San Wang performed the experiments and wrote the paper. Shukui Niu reviewed and edited the manuscript. All authors read and approved the manuscript.

Conflicts of Interest: The authors declare no conflict of interest. 


\section{References}

1. Pyne, S.J.; Andrews, P.L.; Laven, R.D. Introduction to Wildland Fire Science; Wiley: New York, NY, USA, 1996.

2. Peterson, D.L.; Johnson, M.C.; Agee, J.K.; Jain, T.B.; McKenzie, D.; Reinhardt, E.D. Forest Structure and Fire Hazard in Dry Forests of the Western United States; General Technical Report PNW-GTR-628; United States Department of Agriculture: Washington, DC, USA, 2005; p. 30.

3. Menning, K.M.; Stephens, S.L. Fire climbing in the forest: A semi-qualitative, semiquantitative approach to assessing ladder fuel hazards. West. J. Appl. For. 2007, 22, 88-93.

4. Alexander, M.E. Help with making crown fire hazard assessments. In Proceedings of the Protecting People and Homes from Wildfire in the Interior West: Proceedings of the Symposium and Workshop, Missoula, MT, USA, 6-8 October 1988; Fischer; Fischer, W.C., Arno, S.F., Eds.; USDA Forest Service: Washington, DC, USA, 1988.

5. Scott, J.H.; Reinhardt, E.D. Assessing Crown Fire Potential by Linking Models of Surface and Crown Fire Potential; Research Paper RMRS-29; USDA Forest Service, Rocky Mountain Research Station: Washington, DC, USA, 2001.

6. $\mathrm{Xu}, \mathrm{L}$. The freezing weather and forest fire. For. Fire Prev. 1992, 3, $26-27$.

7. Wang, J.H. Forest Fire Hazardous Areas Based on RS and GIS in Panzhihua; Beijing Forestry University: Beijing, China, 2012.

8. Li, F.J. Status of Forest Resources and Sustainable Management Countermeasures in Yanbian Country, Panzhihua; Sichuan Agricultural Uniersity: Ya'an, China, 2009.

9. Li, D. The Relationship between Forest Fire and Meterological Factors in the Key Areas of Sichuan Province; Beijing Forestry University: Beijing, China, 2013.

10. Rothermel, R.C. A Mathematical Model for Predicting Fire Spread in Wildland Fuels; Res. Pap. INT-115; USDA Forest Service, Intermountain Forest and Range Experiment Station: Ogden, UT, USA, 1972; p. 40.

11. Wu, Z.W.; He, H.S.; Liu, X.M.; Deng, H.; He, W.; Li, X.; Li, S.; Song, G.; Wang, Q. Relationship between Loading of Dead Forest Fuels in Surface Soil and Environmental Factors in Fenglin Nature Reserve. J. Northest For. Univ. 2011, 39, 52-55.

12. Sandbergh, D.; Ottmar, R.D.; Cushon, G.H. Characterizing fuels in the 21st century. Int. J. Wildland Fire 2001, 10, 381-387. [CrossRef]

13. Stephens, S.L.; Moghaddas, J.J.; Edminster, C.; Fiedler, C.E.; Haase, S.; Harrington, M.; Keeley, J.E.; Knapp, E.E.; McIver, J.D.; Metlen, K.; et al. Fire treatment effects on vegetation structure, fuels, and potential fire severity in western US Forests. Ecol. Appl. 2009, 19, 305-320. [CrossRef] [PubMed]

14. Niu, S.K. Fire Behavior and Fuel Spatial Continuity of Major Forest Types in the Mountainous Area, Beijing; Beijing Forestry University: Beijing, China, 2013.

15. Stambaugh, M.C.; Dey, D.C.; Guyette, R.P.; He, H.S.; Marschall, J.M. Spatial patterning of fuels and fire hazard across a central US deciduous forest region. Landsc. Ecol. 2011, 26, 923-935. [CrossRef]

16. Uhl, C.; Kauffman, J.B. Deforestation, fire susceptibility, and potential tree responses to fire in the eastern amazon. Ecology 1990, 71, 437-449. [CrossRef]

17. Hornby, L.G. Fire Control Planning in the Northern Rocky Mountain Region; Progress Report No. 1; USDA Forest Service, Northern Rocky Mountain Forest and Range Experiment Station: Ogden, UT, USA, 1936.

18. Albini, F.A. Estimating Wildfire Behavior and Effects; General Technical Report INT-30; USDA Forest Service, Intermountain Forest and Range Experiment Station: Ogden, UT, USA, 1976.

19. Andrews, P.L. Behave: Fire Behavior Prediction and Fuel Modeling System-BURN Subsystem, Part 1; USDA Forest Service: Washington, DC, USA, 1986.

20. Zheng, H.N. Study on control measures of forest fires in southwest. Fire Saf. Sci. 1996, 1, 8-12.

21. Hu, H.; Zhang, Z.; Wu, X. Type Classification of Forest Fuel in Tahe Forestry Bureau Based on Remote Sensing. J. Northeast For. Univ. 2007, 7, 20-21.

22. Wang, S.; Chen, F.; Li, D. Vertical distribution characteristics of fuels in Pinus yunnanensis and its influence factors. Chin. J. Applly Ecol. 2013, 24, 331-337.

23. Tian, X.R. Influences of ice storm on fuels in southern Sichuan. Fire Saf. Sci. 2011, 11, 43-47.

24. Mitsopoulos, I.D.; Dimitrakopoulos, A.P. Canopy fuel characteristics and potential crown fire behavior in Aleppo pine (Pinus halepensis Mill.) forests. Ann. For. Sci. 2007, 64, 287-299. [CrossRef] 
25. Fernandes, P.M. Combining forest structure data and fuel modelling to classify fire hazard in portugal. Ann. For. Sci. 2009, 66, 415. [CrossRef]

26. Mou, K.H.; Wang, J.X.; Ma, Z.G. Study on combustibility of forest (Pinus Yunnanensis Faranch) in west of Panzhihua. J. Sichuan For. Sci. Technol. 1991, 12(2), 28-36.

27. Fan, J.R.; Zhang, Z.Y.; Li, L.H. Mountain demarcation and mountainous area divisions of Sichuan Province. Geogr. Res. 2015, 34, 65-73.

28. Zhang, J.Q.; Wang, C.L.; Wang, D.X. Study on relationship between crown fire and flammable fuel in interlayer. Fire Saf. Sci. 1995, 4, 5-9.

29. Alvarez, A.; Gracia, M.; Retana, J. Fuel types and crown fire potential in Pinus halepensis forests. Eur. J. For. Res. 2012, 131, 463-474. [CrossRef]

30. Lemmon, P.E. A spherical densiometer for estimating forest overstory density. For. Sci. 1956, 1, 314-320.

31. Liu, S.Q.; Shen, Z.H.; Sun, Y.L. Elementary discussions on the application of forest compass in Geological Profile Survey. Jiangxi Build. Mater. 2015, 2, 214.

32. Deeming, J.E.; Burgan, R.E.; Cohen, J.D. The National Fire-Danger Rating System-1978; General Technical Report INT-39; USDA Forest Service: Washington, DC, USA, 1977; p. 6.

33. Keyser, T.; Smith, F.W. Influence of Crown Biomass Estimators and Distribution on Canopy Fuel Characteristics in Ponderosa Pine Stands of the Black Hills. For. Sci. 2010, 56, 156-165.

34. Matthews, S. Effect of drying temperature on fuel moisture content measurements. Int. J. Wildland Fire 2010, 19, 800-802. [CrossRef]

35. Brown, J.K. Handbook for Inventorying Down Woody Material; General Technical Report INT-16; USDA Forest Service, Intermountain Forest and Range Experiment Station: Ogden, UT, USA, 1974; p. 24.

36. Lin, Q.Z.; Shu, L.F. Forest Fire Introduction; University of Science and Technology of China Press: Hefei, China, 2003; pp. 142-148.

37. Hu, H.Q. Forest Fire Ecology and Management; China Forestry Publishing House: Beijing, China, 2005; pp. $17-91$.

38. Zhou, Y.F.; Zhou, G.M.; Yu, S.Q.; Xu, X.J.; Jin, W. Spatial distribution of combustible substance of Schima superba stands in Zhejiang Province, Eastern China. J. Beijing For. Univ. 2008, 30, 99-107.

39. Kucuk, O.; Bilgili, E.; Saglam, B. Estimating crown fuel loading for calabrian pine and Anatolian black pine. Int. J. Wildland Fire 2008, 17, 147-154. [CrossRef]

40. Rothermel, R.C. Predicting behavior and size of crown fires in the Northern Rocky Mountains; Intermountain Forest and Range Experiment Station of USDA Forest Service: Ogden, UT, USA, 1991; pp. 1-46.

41. Andrews, P.L.; Bevins, C.D.; Seli, R.C. BehavePlus Fire Modeling System User's Guide; General Technical Report RMRS-GTR-106; USDA Forest Service: Washington, DC, USA, 2008.

42. Graham, J.B.; McCarthy, B.C. Fuel and fire dynamics in eastern mixed-oak forests. In Proceedings of the Conference on Fire in Eastern Oak Forests: Delivering Science to Land Managers, Columbus, OH, USA, 15-17 November 2005; General Technical Report NRS-P-1. USDA Forest Service, Northern Research Station: Newtown Square, PA, USA, 2006; p. 278.

43. Cruz, M.G.; Alexander, M.E.; Wakimoto, R.H. Assessing canopy fuel stratum characteristics in crown fire prone fuel types of western North America. Int. J. Wildland Fire 2003, 12, 39-50. [CrossRef]

44. Johnson, E.A. Fire and Vegetation Dynamics: Studies from the North American Boreal Forest; Cambridge University Press: London, UK, 1992; p. 129.

45. Scott, J.H. Fuel Reduction in Residential and Scenic Forests: A Comparison of Three Treatments in a Western Montana Ponderosa Pine Stand; Research Paper RMRS-RP-5; USDA Forest Service, Rocky Mountain Research Station: Ogden, UT, USA, 1998; p. 19.

46. Ascoli, D.; Lonati, M.; Marzano, R.; Bovio, G.; Cavallero, A.; Lombardi, G. Prescribed burning and browsing to control tree encroachment in southern european heathlands. For. Ecol. Manag. 2013, 289, 69-77. [CrossRef]

47. Hall, S.A.; Burke, I.C. Considerations for characterizing fuels as inputs for fire behavior models. For. Ecol. Manag. 2006, 227, 102-114. [CrossRef]

48. Albrecht, M.A.; Mccarthy, B.C. Effects of prescribed fire and thinning on tree recruitment patterns in central hardwood forests. For. Ecol. Manag. 2006, 226, 88-103. [CrossRef]

(C) 2016 by the authors; licensee MDPI, Basel, Switzerland. This article is an open access article distributed under the terms and conditions of the Creative Commons by Attribution (CC-BY) license (http:/ / creativecommons.org/licenses/by/4.0/). 